\title{
Analisa Pengendalian Persediaan Suku Cadang Pada PT. XYZ Dengan Metode Analisis ABC
}

\author{
Eka Sofia. A ${ }^{a, 1, *}$, Darno ${ }^{\text {b,2 }}$, Mitha Otik Wiraswati ${ }^{\text {b,3 }}$, Dewi Agustya Ningrum ${ }^{\text {b,4 }}$ \\ ${ }^{a, b}$ Fakultas Ekonomi dan Bisnis, Universitas Maarif Hasyim Latif, Sidoarjo, Indonesia \\ ${ }^{1}$ ekasofia665@gmail.com*; ${ }^{2}$ darno@dosen.umaha.ac.id; ${ }^{3}$ mitha_otik@dosen.umaha.ac.id; \\ ${ }^{4}$ dewi_agustyaningrum@dosen.umaha.ac.id \\ * corresponding author
}

\section{ARTICLE INFO}

\section{Article History}

Received

Revised

Accepted

Keywords Inventory Control; ABC Analysis Methode

\begin{abstract}
Inventory can be interpreted as a stock of goods to be sold or used at a certain time,without the inventory the company will run the risk and can not meet costomer demand. This research was conducted to analyze spare part inventory using ABC analysis method and EOQ method at PT. Adiprima Suraprinta, Gresik.

The results of this study are there there are 4 spare parts inventory items in group A with a cumulative percentage of $8,59 \%$ by absorbing a budget of $56,78 \%$, there are 5 spare parts inventory items in group B with a cumulative percentage of $18,47 \%$ by absorbing a budget of $24,15 \%$, there are 17 spare parts inventory items in group $\mathrm{C}$ with a cumulative percentage of $72,92 \%$ by absorbing a budget of $10 \%$.
\end{abstract}

\section{PENDAHULUAN}

\section{Latar Belakang}

Perkembangan ekonomi diindonesia semakin menujukkan peningkatan baik dibidang jasa maupun dagang. Hal ini ditandai dengan semakin banyak perusahaan-perusahaan baru sehingga semakinketatnya persaingan. Dengan semakin ketatnya persaingan maka mendorong perusahaan untuk menetapkan pengendalian terhadap persediaan. Persediaan digunakan untuk menghindari stockout atau stagnant, sehingga permintaan dan persediaan dapat seimbang.

Persediaan digunakan untuk menjamin kelancaran produksi tetapi persediaan dalam perusahaan tidak boleh terlalu banyak. Jika persediaan terlalu banyak maka dapat menimbulkan biaya penyimpanan yang besar dan sebaliknya jika persediaan tidak mencukupi kebutuhan maka akan menimbulkan kekurangan stock.

Perusahaan yang tumbuh dan berkembang memerlukan pengendalian terhadap persediaan, baik persediaan yang mendukung proses produksi maupun yang memperlancar dalam kegiatan produksi, untuk mewujudkannya diperlukan berbagai macam faktor pendukung.

Persediaan suku cadang sangat penting dalam proses produksi selain persediaan bahan baku karena jalannya operasi pada mesin perusahaan tergantung pada persediaan suku cadang.

PT. Adiprima Suraprinta merupakan perusahan yang memproduksi kertas dari bahan daur ulang, sebaik apapun sistem dan prosedur persediaan suku cadang yang diterapkan jika tanpa adanya pengendalian maka akan merugikan perusahaan, dengan demikian pengendalian merupakan teknik yang sangat penting agar persediaan dapat mencapai pada titik yang optimal pada saat dibutuhkan serta waktu yang tepat untuk melakukan pengadaan kembali.

Pengendalian pada PT. Adiprima Suraprinta dapat menggunakan metode analisis ABC karen banyaknya jumlah item pada kelompok A menyebabkan tingginya nilai volume tahunan rupiah sehingga persediaan pada kelas A memerlukan perhatian yang tinggi dalam pengadaannya, karena menimbulkan biaya yang tinggi, pengendaliannya harus dilakukan secara ketat, kelas B memilik nilai volume tahunan rupiah menengah, kelas $\mathrm{C}$ memiliki nilai volume tahunan rupiah yang rendah.

Analisis ABC digunakan untuk mengkalifikasikan persediaan menurut harga dan dapat melakukan pengawasan yang lebih ketat terhadap suku cadang yang mempunyai harga relatif mahal. 


\section{Rumusan Masalah}

1. Bagaimana model pengendalian persediaan pada PT. Adiprima Suraprinta?

2. Bagaimana model pengendalian persediaan menggunakan metode analisis $\mathrm{ABC}$ ?

\section{Tujuan Penelitian}

1. Mengidentifikasi sistem pengendalian persediaan pada PT. Adiprima Suraprinta.

2. Menganalisa pengendalian pada PT. Adiprima Suraprinta menggunakan metode analisis ABC.

\section{LANDASAN TEORI}

Sofyan Assauri, (2016:176) menyatakan bahwa pengendalian adalah salah satu kegiatan dari urutan kegiatan-kegiatan yang berurutan serta erat satu sama lain dalam seluruh opersi produksi perusahaan tersebut sesuai dengan apa yang telah direncanakan lebih dahulu, baik waktu, jumlah, kuantitas, maupun biayanya.

Mulyadi dan Jhony Setiawan, (2000:3) menyatakan bahwa pengendalian merupakan sistem untuk mengimplementasikan dan mengendalikan rencana kegiatan. Dalam pengendalian terdapat dua hal yang penting yaitu tujuan yang akan diwujudkan dan perilaku tertentu yang diharapkan.

Sofyan Assauri, (2016:18) menyatakan bahwa tujuan pengendalian adalah:

Menjaga jangan sampai perusahaan kehabisan persediaaan, sehingga dapat mengkibatkan terhentinya kegiatan operasi.

a. Menjaga agar pembentukan persediaan oleh perusahaan tidak terlalu besar atau kelebihan sehingga biayabiaya yang ditimbulkan dari persediaan tidak terlalu besar.

b. Menjaga agar pembelian secara kecil-kecil dapat dihindari, karena hal ini dapat berakibat biaya pemesanan menjadi besar.

c. Menjaga agar pembeli secara kecil-kecil dapat dihindari, karena hal ini dapat berakibat biaya pemesanan menjadi besar.

Sistem dan teknik pengendalian persediaan harus didasari dengan prinsip-prinsip:

a. Persediaan diciptakan dari pembelian bahan dan suku cadang, tambahan biaya pekerjaan dan overhead untuk mengelolah bahan menjadi barang jadi.

b. Persediaan berkurang melalui penjualan dan kerusakan.

c. Perkiraan yang tepat atas skedul penjualan dan produksi merupakan hal yang esensial bagi pembelian, penagihan, dan investasi bahan yang efisien.

d. Kebijakan manajemen yang berupa menciptakan keseimbangan antara keragaman dan kualitas persediaan bagi operasi yang efisien dengan biaya pemilikan persediaan tersebut merupakan faktor yang paling utama dalam menentukan investasi perusahaan.

e. Pemesanan bahan merupakan tanggapan terhadap perkiraan dan penyusunan rencana pengendalian produksi.

f. Pencatatan persediaan saja tidak akan mencapai pengendalian atas persediaan. Matz, (1994:230).

Mulyadi, (2005:553) menyatakan bahwa persediaan adalah sebagian barang-barang yang dimiliki atau disimpan di perusahaan yang terdiri dari produk jadi, produk dalam proses, bahan baku, bahan penolong, bahan habis pakai, suku cadang, dan sebagainya yang dimaksudkan untuk dijual kembali.

Persediaan adalah barang-barang yang disimpan untuk digunakan atau dijual pada masa atau priode yang akan datang. Menurut Ristono, (2009)

I Made Sudana, (225:2011) menyatakan bahwa persediaan merupakan salah satu komponen modal kerja yang tingkat likuiditasnya palin rendah dibandingkan dengan komponen modal kerja lainnya.

Barry Render dan Jay Hazer, (2011:314) menyatakan bahwa tujuan persediaan adalah:

a.) Untuk memberikan suatu stok barang-barang agar dapat memenuhi permintaan yang diantisipasi akan timbul dari konsumen.

b.) Untuk menghindari dari kekurangan stok, kekurangan pasokan, masalah mutu atau pengiriman yang tidak tepat.

c.) Untuk menjaga agar operasi dapat berjalan dengan baik. 
Sofyan Assauri, (2016:240) menyatakan bahwa persediaan itu dapat dibedakan atau dikelompokkan menurut jenis dan posisi barang didalam urutan pengerjaan produk yaitu:

1. Persediaan bahan baku yaitu persediaan barang-barang berwujud yang digunkan dalam proses produksi.

2. Persediaan bagian produk yang di beli yaitu persediaan barang-barang yang terdiri atas parts yang di terima dari perusahaan lain, yang dapat secara langsung diolah dengan parts yang lain tanpa melalui proses produksi sebelumnya.

3. Persediaan bahan pembantu yaitu persediaan yang diperlukan untuk membantu dalam proses produksi.

4. Persediaan barang setengah jadi yaitu persediaan barang yang keluar dari tiap-tiap bagian yang telah menjadi suatu bentuk tetapi perlu di proses kembali.

5. Persediaan barang jadi yaitu persedian barang-barang yang telah selesai diproses atau diolah dan siap untuk dijual.

Haizer dan Render, (2015:82) menyatakan bahwa persediaan dapat melayani beberapa fungsi yang menambah flekibilitas bagi operasi perusahaan yaitu:

a. Decouple atau memisahkan beberapa tahapan dari proses produksi.

b. Melakukan decouple perusahaan dari fluktuasi permintaan dan menyediakan persediaan barang-barang yang akan memberikan pilihan bagi pelanggan.

c. Mengambil keuntungan dari diskon kuantitas karena pembelian dalam jumlah besar dapat mengurangi biaya pengiriman barang.

d. Melindungi inflasi dan kenaikan harga.

Suku cadang adalah suatu alat yang mendukung pengadaan barang untuk keperluan peralatan yang digunakan dalam proses produksi. Indrajit dkk, (2006)

Klasifikasi suku cadang menurut penggunanya dibagi menjadi beberapa jenis yaitu:

1) Suku cadang habis pakai

Suku cadang yang akan habis dan rusak, kerusakan ini terjadi sewaktu-waktu. Oleh karena itu pengaturan persediaannya haruslah sedemikian rupa sehingga sewaktu-waktu diperlukan selalu tersedia atau dapat diadakan dalam waktu singkat sehingga tidak menganggu jalannya produksi.

2) Suku cadang pengganti

Suku cadang yang pengantiaannya dilakukan pada waktu diadakan perbaikan besar-besaran. Waktu pengantian ini biasanya dapat dijadwalkan sesuai dengan rekomendasi pabrik pembuat peralatan tersebut.

3) Suku cadang jaminan

Suku cadang ini biasanya hampir tidak pernah rusak, dan apabila rusak dapat menghentikan operasi produksi. suku cadag ini biasanya bentuknya besar, harganya mahal, dan waktu pembuatannya lama. Indrajit dkk (2006).

\section{Metode analisis ABC}

Haizer dan Render, (2010:84) menyatakan bahwa analisis ABC merupakan sebuah metode membagi persediaan yang ada menjadi tiga klasifikasi berdasarkan volume tahunan dalam jumlah uang.

I Made Sudana, $(2011,233)$ menyatakan bahwa persediaan yang menerapkan klasifikasi ABC adalah semua persediaan harus bisa dimasukkan ke dalam salah satu kelompok persediaan yaitu:

1. Kelompok A, merupakan persediaan yang harga per satuannya tinggi dan kontribusi terhadap penjualan juga tinggi.

2. Kelompok B, merupakan persediaan yang harganya lebih renda dari kelompok A dan kontribusi terhadap penjualan sedang.

3. Kelompok $\mathrm{C}$ merupakan persediaan yang harganya rendah dan kontribusi terhadap penjualan juga rendah.

Johns dan Harding, (2001) menyatakan bahwa klasifikasi ABC untuk kelompok A sebanyak 15\% dari total item dan menyerap dana sebesar $75 \%$, kelompok B sebanyak $25 \%$ dari total item dan menyerap dana sebesar $15 \%$, kelompok $\mathrm{C}$ sebanyak $60 \%$ dari total item dan menyerap dana sebesar $10 \%$. 


\section{Penelitian Terdahulu}

Analisa ABC dalam pengendalian persediaan spare part jenis oli sepeda motor di bengkel piramida motor Tulungagung, Lilia Pasca Riani, Bayu Wiyono, 2016

Menyatakan bahwa tujuan penelitian ini adalah menganalisia pengendalian pengendalian sparepart jenis oli sepeda motor. Penelitian dilakukan di bengkel piramida yang berlokasi di kabupaten Tulungagung. Desain penelitian dalam penelitian ini adalah studi kasus, yakni menemukan permasalahan di lokasi penelitian kemudian menganalisa dan menemukan pemecahan masalah sesuai dengan teori-teori yang ada. Permasalahan yang diteliti mengenai pengendalian persediaan menggunakan model klasifikasi ABC.

Hasil dari penelitian ini adalah terdapat 6 item persediaan jenis oli yang masuk kelas A Yaitu Top One, Endure, Supersyn, Ahm Mpx, Federal Oil, Dan Mesran. Sedangkan jenis oli yang masuk kelas B adalah Yamahalube, Castrol Power One, dan SGO. Dan yang masuk kelas C adalah Castrol Active, Evalube, dan GGI.

\section{METODE}

\section{Objek dan Ruang Lingkup Penelitian}

Penulis memfokuskan penelitian ini pada pengendalian persediaan suku cadang habis pakai pada PT. Adiprima Suraprinta menggunakan metode analisis ABC. Penelitian ini dilaksanaklan di PT. Adiprima Suprarinta yang berada di Desa Sumengko Kecamatan Wringinanom Kabupaten Gresik.

Ruang lingkup ini merupakan batasan studi yang memberi batasan penelitian guna untuk lebih fokus pada penelitian agar tidak terlalu melebar bahkan menimbulkan multitafsir kepada para pembaca. Karena luasnya permasalahan yang diteliti maka penulis hanya membatasi masalah pada pengendalian persediaan suku cadang pada bahan habis pakai menggunakan metode analisis ABC.

\section{Metode Penelitian}

Metode penelitian yang digunakan pada penelitian ini adalah penelitian deskriptif dengan bantuan analisis kualitatif.

Suryabrata, (2013:14) menyatakan bahwa penelitian deskriptif merupakan penelitian yang bermaksut untuk membuat pencandraan (deskriptif) mengenai situasi-situasi atau kejadian-kejadian dengan tujuan membuat gambaran secara sistematis, faktual, dan akurat mengenai fakta-fakta dan sifat populasi daerah tertentu.

\section{Teknik Pengumpulan Data}

Teknik pengumpulan data yang dilakukan oleh peneliti yaitu:

a. Penelitian Kepustakaan

Penelitian ini dilakukan dengan cara mempelajari dan menggunakan buku-buku literatur, jurnal, maupun skripsi yang berhubungan dengan penelitian ini.

b. Penelitian Lapangan

Penelitian lapangan dilakukan dengan teknik

1. wawancara yaitu teknik yang dilakukan dengan cara bertanya langsung kepada pihak yang berhubungan dengan penelitian guna memperoleh informasi yang lengkap dan akurat.

2. Observasi yaitu teknik yang dilakukan dengan cara mengamati langsung proses penyimpanan hingga pengeluaran persediaan yang ada di perusahaan agar dapat memperoleh data-data yang berhubungan dengan penelitian.

\section{Teknik Analisis Data}

Teknik yang digunakan dalam menganalisis data adalah analisis deskriptif kuantitatif yaitu analisis yang digunakan untuk menguraikan dan menggambarkan penggendalian persediaan serta mengklasifikasikan persediaan kedalam tiga kelompok yaitu kelompok A, kelompok B, kelompok $\mathrm{C}$, dengan langkah-langkah sebagai berikut:

1. Data pertama terdapat nama barang dan jumlah pemakaian suku cadang pada tahun 2019 kemudian dikalikan dengan harga

2. Mengurutkan data dari nilai tertinggi hingga terrendah

3. Menghitung nilai kumulatif 
4. Menghitung prosentase nilai kumulatif

5. Mengkasifikasikan persediaan kedalam kelompok A,B,C.

\section{HASIL dan PEMBAHASAN}

\section{Gambaran Umum Objek Penelitian}

PT. Adiprima Suraprinta terletak di Desa Sumengko, Kecamatan Wringinanom, Kabupaten Gresik. PT. Adiprima Suraprinta memiliki luas kurang lebih sebesar 10,3 Ha, untuk bangunan seluas 8 Ha dan sisanya digunakan untuk fasilitas jalan, pagar, taman dan fasilitas lainnya.

PT. Adiprima Suraprinta didirikan pada tangal 11 November 1994 yang dimuat dalam akta No. 40 oleh Nansijan Sohandjaja.,SH yang merupakan salah satu notaris di Surabaya, dan telah mendapat persetujuan dari mentri kehakiman pada tanggal 14 Desember 1994 dengan No.0218377.HT.01.01.94 dan memiliki 3 mesin produksi. Mesin pertamanya PM1 mulai menjalankan proses produksi pada tahun 1995 dengan kapasitas sekitar 150 MTS per hari.

\section{Visi dan Misi PT. Adiprima Suraprinta}

Visi PT. Adiprima Surprinta

Menjadi perusahaan manufaktur kertas yang ramah lingkungan dan memberikan kontribusi terbesar kepada pemangku kepentingan dan lingkungan sekitarnya.

Misi PT. Adiprima Suraprinta

Melakukan proses manufaktur yang efisien, ramah lingkungan dan berkelanjutan serta tanggung jawab bagi semua pemangku kepentingan.

\section{Pengendalian Persediaan pada PT. Adiprima Suraprinta}

Persediaan pada PT. Adiprima Suraprinta di bagi menjadi 2 jenis yaitu

1. Persediaan umum yaitu persediaan barang yang biasanya digunakan diluar proses produksi, misalnya: sarung tangan kain, alat tulis kantor, dan lain sebagainya biasanya persediaan ini dipesan sendiri oleh pihak gudang SPI.

2. Persediaan khusus yaitu persediaan barang yang meliputi alat-alat mesin untuk proses prouksi, misalnya: batu gerinda, mur, baut, dan lain sebagainya. Biasanya persediaan ini dipesan oleh pemakai masingmasing bagian (departemen) yang talah disetujui oleh bagian gudang SPI untuk dilaporkan ke bagian pembelian untuk dilakukan pemesanan.

Penerimaan persediaan barang umum di lakukan pengecekan oleh petugas gudang sendiri, dan untuk penerimaan persediaan barang khusus maka pengecekan dilakukan oleh departemen pemesan/ pemakai barang tersebut. Jika barang tersebut diterima maka pihak gudang imput data penerimaan barang ke sistem serta mengisi karto stock barang dan diberi tanggal pada setiap barang yang masuk ke gudang, ini digunakan agar mengetahui barang mana yang harus dipakai lebih dahulu, karena dalam proses pengeluaran barang menggunakan metode FIFO ( masuk pertama keluar pertama).

\section{Pengendalian Persediaan Menggunakan Metode analisis ABC}

Klasifikasi pengendlian berdasarkan metode analisis ABC dilakukan dengan cara mengelompokkan persediaan berdasarkan nilai volume barang.

Tahap-tahap yang dilakukan untuk melakukan pengendalian menggunakan metode analisis $\mathrm{ABC}$ adalah sebagai berikut:

1. Menghitung jumlah pemakaian suku cadang pada tahun 2019 untuk setiap satuan unit dan daftar harga serta menghitung nilai rupiah pada setiap unit.

2. Mengurutkan setiap jenis suku cadang yang mempunyai nilai investasi dari yang btertinggi hingga terrendah.

3. Menghitung nilai investasi kumulatif pada masing-masing item suku cadang.

4. Menghitung presentase nilai kumulatif pada masing-masing suku cadang

5. Mementukan kelompok persediaan suku cadang untuk setiap jenis barang berdasarkan presentase nilai kumulatif untuk mengklasifikasikan persediaan berdasarkan metode analisis ABC.

Jenis suku cadang beserta harga yang telah dihitung nilai rupiah dapat dilihat pada tabel 1 berikut: 
ISSN 2686-1577

Tabel 1. Data suku cadang dan perhitungan nilai rupiah

\begin{tabular}{llcrr}
\hline No & \multicolumn{1}{c}{ Nama barang } & Jumlah Pemakaian & harga & Nilai Rupiah \\
\hline $\mathbf{1}$ & Kawat Las LB-52 2,6 mm & 45 & 32.000 & 1.440 .000 \\
$\mathbf{2}$ & Kawat Las LB-52 3,2 mm & 42 & 34.000 & 1.428 .000 \\
$\mathbf{3}$ & Kawat Las RB-26 2,6 mm & 15 & 33.000 & 495.000 \\
$\mathbf{4}$ & Kawat Las RB-26 3,2 mm & 16 & 35.000 & 560.000 \\
$\mathbf{5}$ & Kawat las stainless 308 2,6 mm & 3 & 42.500 & 127.500 \\
$\mathbf{6}$ & Kawat las stainless 308 3,2 mm & 20 & 47.500 & 950.000 \\
$\mathbf{7}$ & Kawat las stainless 309 2,6 mm & 14 & 58.500 & 819.000 \\
$\mathbf{8}$ & Kawat las stainless 309 3,2 mm & 11 & 61.000 & 671.000 \\
$\mathbf{9}$ & Baut L M6 X 30 BAJA & 44 & 12.000 & 528.000 \\
$\mathbf{1 0}$ & Baut L M8 X 75 mm Baja + Mur & 56 & 5.000 & 280.000 \\
$\mathbf{1 1}$ & Baut L M5 X 40 SS & 30 & 2.000 & 60.000 \\
$\mathbf{1 2}$ & Baut L M5 X 15 SS + RING & 20 & 1.500 & 30.000 \\
$\mathbf{1 3}$ & Baut L 6 X 15 SS & 25 & 1.000 & 25.000 \\
$\mathbf{1 4}$ & Baut L M6 X 10 SS & 10 & 800 & 8.000 \\
$\mathbf{1 5}$ & Baut L M6 X 60 SS & 13 & 6.000 & 78.000 \\
$\mathbf{1 6}$ & Baut L M8 X 20 SS & 98 & 2.500 & 245.000 \\
$\mathbf{1 7}$ & Baut L M8 X 40 SS & 120 & 6.000 & 720.000 \\
$\mathbf{1 8}$ & Baut L M12 X 25 SS & 301 & 11.000 & 3.311 .000 \\
$\mathbf{1 9}$ & Baut L M12 X 40 SS & 75 & 17.500 & 1.312 .500 \\
$\mathbf{2 0}$ & Batu Gerinda Potong 4" (100 X 3 X 16) & 731 & 9.000 & 6.579 .000 \\
$\mathbf{2 1}$ & Batu Gerinda Potong 7" / 180 X 3 X 22 & 1.354 & 16.000 & 21.664 .000 \\
$\mathbf{2 2}$ & Batu Gerinda Potong 14" & 29 & 28.000 & 812.000 \\
$\mathbf{2 3}$ & Batu Gerinda Selep Dia 4 /100 X 6 X 16 & 808 & 15.500 & 12.524 .000 \\
$\mathbf{2 4}$ & Batu Gerinda Selep 180 X 6 X 22 & 192 & 30.000 & 5.760 .000 \\
$\mathbf{2 5}$ & Sarung tangan & 4.532 & 1.500 & 6.798 .000 \\
$\mathbf{2 6}$ & Masker kain & 4.727 & 2.000 & 9.454 .000 \\
\hline
\end{tabular}

Tabel 1 tersebut dapat diketahui jenis suku cadang serta perhitungan nilai rupiah. Perhitungan nilai rupiah diperoleh dari mengalikan herga per unit suku cadang dengan jumlah pemakaian.

Tabel 2. Urutan nilai rupiah dari nilai tertinggi

\begin{tabular}{llcrr}
\hline No. & \multicolumn{1}{c}{ Nama Barang } & $\begin{array}{c}\text { Jumlah } \\
\text { pemakaian }\end{array}$ & Harga & Nilai Rupiah \\
\hline $\mathbf{2 1}$ & Batu Gerinda Potong 7" / 180 X 3 X 22 & 1354 & 16.000 & 21.664 .000 \\
$\mathbf{2 3}$ & Batu Gerinda Selep Dia 4 /100 X 6 X 16 & 808 & 15.500 & 12.524 .000 \\
$\mathbf{2 6}$ & Masker kain & 4.727 & 2.000 & 9.454 .000 \\
$\mathbf{2 5}$ & Sarung tangan & 4.532 & 1.500 & 6.798 .000 \\
$\mathbf{2 0}$ & Batu Gerinda Potong 4" (100 X 3 X 16) & 731 & 9.000 & 6.579 .000 \\
$\mathbf{2 4}$ & Batu Gerinda Selep 180 X 6 X 22 & 192 & 30.000 & 5.760 .000 \\
$\mathbf{1 8}$ & Baut L M12 X 25 SS & 301 & 11.000 & 3.311 .000 \\
$\mathbf{1}$ & Kawat Las LB-52 2,6 mm & 45 & 32.000 & 1.440 .000 \\
$\mathbf{2}$ & Kawat Las LB-52 3,2 mm & 42 & 34.000 & 1.428 .000 \\
$\mathbf{1 9}$ & Baut L M12 X 40 SS & 75 & 17.500 & 1.312 .500 \\
$\mathbf{6}$ & Kawat las stainless 308 3,2 mm & 20 & 47.500 & 950.000 \\
$\mathbf{7}$ & Kawat las stainless 309 2,6 mm & 14 & 58.500 & 819.000 \\
$\mathbf{2 2}$ & Batu Gerinda Potong 14" & 29 & 28.000 & 812.000 \\
$\mathbf{1 7}$ & Baut L M8 X 40 SS & 120 & 6.000 & 72.0000 \\
$\mathbf{8}$ & Kawat las stainless 309 3,2 mm & 11 & 61.000 & 671.000 \\
$\mathbf{9}$ & Baut L M6 X 30 BAJA & 44 & 12.000 & 528.000 \\
$\mathbf{4}$ & Kawat Las RB-26 3,2 mm & 16 & 35.000 & 560.000 \\
$\mathbf{3}$ & Kawat Las RB-26 2,6 mm & 15 & 33.000 & 495.000 \\
$\mathbf{1 0}$ & Baut L M8 X 75 mm Baja + Mur & 56 & 5.000 & 280.000 \\
$\mathbf{1 6}$ & Baut L M8 X 20 SS & 98 & 2.500 & 245.000 \\
$\mathbf{5}$ & Kawat las stainless 308 2,6 mm & 3 & 42.500 & 127.500 \\
$\mathbf{1 5}$ & Baut L M6 X 60 SS & 13 & 6.000 & 78.000 \\
$\mathbf{1 1}$ & Baut L M5 X 40 SS & 30 & 2.000 & 60.000 \\
$\mathbf{1 2}$ & Baut L M5 X 15 SS + RING & 20 & 1.500 & 30.000 \\
$\mathbf{1 3}$ & Baut L 6 X 15 SS & 25 & 1.000 & 25.000 \\
$\mathbf{1 4}$ & Baut L M6 X 10 SS & 10 & 800 & 8.000 \\
\hline
\end{tabular}

Eka Sofia. A, et al (Analisa Pengendalian Persediaan Suku Cadang Pada PT. XYZ Dengan...) 
Tabel 2 tersebut merupakan urutan suku cadang yang memiliki jumlah nilai rupiah dari yang tertinggi hingga terrendah. Batu gerinda potong 7' 'terdapat pada urutan pertama dan baut LM6X10SS pada urutan terakhir.

Tabel 3.data nilai kumulatif

\begin{tabular}{llcrrr}
\hline No. & \multicolumn{1}{c}{ Nama Barang } & $\begin{array}{c}\text { Jumlah } \\
\text { pemakaian }\end{array}$ & Harga & $\begin{array}{c}\text { Nilai } \\
\text { Rupiah }\end{array}$ & $\begin{array}{c}\text { Nilai } \\
\text { Kumulatif }\end{array}$ \\
\hline $\mathbf{2 1}$ & Batu Gerinda Potong 7" / 180 X 3 X 22 & 1354 & 16.000 & 21.664 .000 & 21.664 .000 \\
$\mathbf{2 3}$ & Batu Gerinda Selep Dia 4 /100 X 6 X & 808 & 15.500 & 12.524 .000 & 34.188 .000 \\
& 16 & 4.727 & 2.000 & 9.454 .000 & 43.642 .000 \\
$\mathbf{2 6}$ & Masker kain & 4.532 & 1.500 & 6.798 .000 & 50.440 .000 \\
$\mathbf{2 5}$ & Sarung tangan & 731 & 9.000 & 6.579 .000 & 57.019 .000 \\
$\mathbf{2 0}$ & Batu Gerinda Potong 4" (100 X 3 X & & & & \\
& 16) & 192 & 30.000 & 5.760 .000 & 62.779 .000 \\
$\mathbf{2 4}$ & Batu Gerinda Selep 180 X 6 X 22 & 301 & 11.000 & 3.311 .000 & 66.090 .000 \\
$\mathbf{1 8}$ & Baut L M12 X 25 SS & 45 & 32.000 & 1.440 .000 & 67.530 .000 \\
$\mathbf{1}$ & Kawat Las LB-52 2,6 mm & 42 & 34.000 & 1.428 .000 & 68.958 .000 \\
$\mathbf{2}$ & Kawat Las LB-52 3,2 mm & 75 & 17.500 & 1.312 .500 & 70.270 .500 \\
$\mathbf{1 9}$ & Baut L M12 X 40 SS & 20 & 47.500 & 950.000 & 71.220 .500 \\
$\mathbf{6}$ & Kawat las stainless 308 3,2 mm & 14 & 58.500 & 819.000 & 72.039 .500 \\
$\mathbf{7}$ & Kawat las stainless 309 2,6 mm & 29 & 28.000 & 812.000 & 72.851 .500 \\
$\mathbf{2 2}$ & Batu Gerinda Potong 14" & 120 & 6.000 & 720.000 & 73.571 .500 \\
$\mathbf{1 7}$ & Baut L M8 X 40 SS & 11 & 61.000 & 671.000 & 74.242 .500 \\
$\mathbf{8}$ & Kawat las stainless 309 3,2 mm & 44 & 12.000 & 528.000 & 74.770 .500 \\
$\mathbf{9}$ & Baut L M6 X 30 BAJA & 16 & 35.000 & 560.000 & 75.330 .500 \\
$\mathbf{4}$ & Kawat Las RB-26 3,2 mm & 15 & 33.000 & 495.000 & 75.825 .500 \\
$\mathbf{3}$ & Kawat Las RB-26 2,6 mm & 56 & 5.000 & 280.000 & 76.105 .500 \\
$\mathbf{1 0}$ & Baut L M8 X 75 mm Baja + Mur & 98 & 2.500 & 245.000 & 76.350 .500 \\
$\mathbf{1 6}$ & Baut L M8 X 20 SS & 3 & 42.500 & 127.500 & 76.478 .000 \\
$\mathbf{5}$ & Kawat las stainless 308 2,6 mm & 13 & 6.000 & 78.000 & 76.556 .000 \\
$\mathbf{1 5}$ & Baut L M6 X 60 SS & 30 & 2.000 & 60.000 & 76.616 .000 \\
$\mathbf{1 1}$ & Baut L M5 X 40 SS & 20 & 1.500 & 30.000 & 76.646 .000 \\
$\mathbf{1 2}$ & Baut L M5 X 15 SS + RING & 25 & 1.000 & 25.000 & 76.671 .000 \\
$\mathbf{1 3}$ & Baut L 6 X 15 SS & 10 & 800 & 8.000 & 76.679 .000 \\
$\mathbf{1 4}$ & Baut L M6 X 10 SS & & & $\mathbf{7 6 . 6 7 9 . 0 0 0}$ & \\
\hline & Jumlah & & & & \\
\hline & & & & &
\end{tabular}

Tahap ketiga yaitu perhitungan nilai kumulatif pada masing-masing suku cadang, dimana perhitungan nilai kumulatif pada batu gerinda potong 7" /180X3X22 sebesar 21.664.000, batu gerinda selep dia 4/100X6X16 sebasar 34.188.000 yang diperoleh dari $(21.664 .000+12.524 .000)$, masker kain sebesar 43.642.000 yang diperoleh dari $(34.188 .000+9.454 .000)$ dan seterusnya. Kemudian akan dihitung prosentase nilai kumulatif pada setiap suku cadang dan mengklasifikasikan suku cadang berdasarkan analisis $\mathrm{ABC}$ yaitu menentukan golongan suku cadang berdasarkan kelompok dengan ketentuan 0-70\% termasuk pada kelompok A, 71-90\% termasuk pada kelompok B, 91-100\% termasuk pada kelompok C yang dapat dilihat pada tabel 4 berikut:

Tabel 4. Perhitungan prosentase nilai kumulatif dan kelompok suku cadang

\begin{tabular}{|c|c|c|c|c|c|c|c|}
\hline No. & Nama Barang & $\begin{array}{c}\text { Jumlah } \\
\text { pemakaian }\end{array}$ & Harga & $\begin{array}{c}\text { Nilai } \\
\text { Rupiah }\end{array}$ & $\begin{array}{c}\text { Nilai } \\
\text { Kumulatif }\end{array}$ & $\begin{array}{c}\text { Prosentase } \\
\text { nilai } \\
\text { kumulatif }\end{array}$ & $\begin{array}{l}\text { Klmpk } \\
\text { suku } \\
\text { cadang }\end{array}$ \\
\hline 21 & Batu Gerinda Potong 7" / 180 X 3 X 22 & 1354 & 16.000 & 21.664 .000 & 21.664 .000 & 28,252846 & $\mathrm{~A}$ \\
\hline 23 & $\begin{array}{l}\text { Batu Gerinda Selep Dia } 4 / 100 \text { X } 6 \text { X } \\
16\end{array}$ & 808 & 15.500 & 12.524 .000 & 34.188 .000 & 44,585871 & A \\
\hline 26 & Masker kain & 4.727 & 2.000 & 9.454 .000 & 43.642 .000 & 56,915192 & A \\
\hline 25 & Sarung tangan & 4.532 & 1.500 & 6.798 .000 & 50.440 .000 & 65,780722 & A \\
\hline 20 & $\begin{array}{l}\text { Batu Gerinda Potong 4" (100 X } 3 \text { X } \\
\text { 16) }\end{array}$ & 731 & 9.000 & 6.579 .000 & 57.019 .000 & 74,360646 & B \\
\hline 24 & Batu Gerinda Selep 180 X 6 X 22 & 192 & 30.0 & 5.7 & 0 & 31 & B \\
\hline 18 & Baut L M12 X 25 SS & 301 & 11.000 & 3.311 .000 & 66.090 .000 & 86,190482 & $\mathrm{~B}$ \\
\hline
\end{tabular}

Eka Sofia. A, et al (Analisa Pengendalian Persediaan Suku Cadang Pada PT. XYZ Dengan...) 


\begin{tabular}{llrrrrrl}
\hline $\mathbf{1}$ & Kawat Las LB-52 2,6 mm & 45 & 32.000 & 1.440 .000 & 67.530 .000 & 88,068441 & B \\
$\mathbf{2}$ & Kawat Las LB-52 3,2 mm & 42 & 34.000 & 1.428 .000 & 68.958 .000 & 89,93075 & B \\
$\mathbf{1 9}$ & Baut L M12 X 40 SS & 75 & 17.500 & 1.312 .500 & 70.270 .500 & 91,642431 & C \\
$\mathbf{6}$ & Kawat las stainless 308 3,2 mm & 20 & 47.500 & 950.000 & 71.220 .500 & 92,881363 & C \\
$\mathbf{7}$ & Kawat las stainless 309 2,6 mm & 14 & 58.500 & 819.000 & 72.039 .500 & 93,949452 & C \\
$\mathbf{2 2}$ & Batu Gerinda Potong 14” & 29 & 28.000 & 812.000 & 72.851 .500 & 95,008412 & C \\
$\mathbf{1 7}$ & Baut L M8 X 40 SS & 120 & 6.000 & 720.000 & 73.571 .500 & 95,947391 & $\mathrm{C}$ \\
$\mathbf{8}$ & Kawat las stainless 309 3,2 mm & 11 & 61.000 & 671.000 & 74.242 .500 & 96,822468 & $\mathrm{C}$ \\
$\mathbf{9}$ & Baut L M6 X 30 BAJA & 44 & 12.000 & 528.000 & 74.770 .500 & 97,511053 & $\mathrm{C}$ \\
$\mathbf{4}$ & Kawat Las RB-26 3,2 mm & 16 & 35.000 & 560.000 & 75.330 .500 & 98,24137 & $\mathrm{C}$ \\
$\mathbf{3}$ & Kawat Las RB-26 2,6 mm & 15 & 33.000 & 495.000 & 75.825 .500 & 98,886918 & $\mathrm{C}$ \\
$\mathbf{1 0}$ & Baut L M8 X 75 mm Baja + Mur & 56 & 5.000 & 280.000 & 76.105 .500 & 99,252077 & $\mathrm{C}$ \\
$\mathbf{1 6}$ & Baut L M8 X 20 SS & 98 & 2.500 & 245.000 & 76.350 .500 & 99,571591 & $\mathrm{C}$ \\
$\mathbf{5}$ & Kawat las stainless 308 2,6 mm & 3 & 42.500 & 127.500 & 76.478 .000 & 99,737868 & $\mathrm{C}$ \\
$\mathbf{1 5}$ & Baut L M6 X 60 SS & 13 & 6.000 & 78.000 & 76.556 .000 & 99,839591 & $\mathrm{C}$ \\
$\mathbf{1 1}$ & Baut L M5 X 40 SS & 30 & 2.000 & 60.000 & 76.616 .000 & 99,917839 & $\mathrm{C}$ \\
$\mathbf{1 2}$ & Baut L M5 X 15 SS + RING & 20 & 1.500 & 30.000 & 76.646 .000 & 99,956963 & $\mathrm{C}$ \\
$\mathbf{1 3}$ & Baut L 6 X 15 SS & 25 & 1.000 & 25.000 & 76.671 .000 & 99,989567 & $\mathrm{C}$ \\
$\mathbf{1 4}$ & Baut L M6 X 10 SS & 10 & 800 & 8.000 & 76.679 .000 & \\
& Jumlah & & & $\mathbf{7 6 . 6 7 9 . 0 0 0}$ & & $\mathbf{2 . 2 7 5 , 1 1 4}$ & $\mathrm{C}$ \\
\hline
\end{tabular}

Tabel 4 dapat diketahui prosentase nilai kumulatif dimana masing-masing suku cadang perhitungan tersebut diperoleh prosentase nilai kumulatif sebagai berikut: Batu Gerinda Potong 7" / 180 X 3 X 22 sebesar 28,252846 yang diperoleh dari $\frac{21.664 .000 \times 100}{76.679 .000}$, Batu Gerinda Selep Dia 4 /100 X 6 X 16 sebesar 44,585871 yang diperoleh dari $\frac{34.188 .000 \times 100}{76.679 .000}$ dan seterusnya. Dalam klasifikasi suku cadang terdapat 4 item pada kelompok A, 5 item pada kelompok B, dan 17 item termasuk pada kelompok C.

Pengelompokkan suku cadang tersebut dapat ditarik kesimpulan yang dapat dilihat pada tabel 5 berikut:

Tabel 5 pengelompokan suku cadang tiap kelompok

\begin{tabular}{ccrcl}
\hline Kelompok & Jumlah item & $\begin{array}{c}\text { Prosentase } \\
\text { kumulatif }\end{array}$ & $\begin{array}{c}\text { Jumlah nilai } \\
\text { rupiah }\end{array}$ & $\begin{array}{c}\text { Prosentase penyerapan } \\
\text { nilai rupiah }\end{array}$ \\
\hline A & 4 & $8,59 \%$ & 50.440 .000 & $56,78 \%$ \\
B & 5 & $18,47 \%$ & 18.518 .000 & $24,15 \%$ \\
C & 17 & $72,92 \%$ & 7.721 .000 & $10 \%$ \\
\hline
\end{tabular}

Tabel 5 dapat diketahui bahwa persediaan suku cadang pada kelompok A memiliki prosentase kumulatif sebesar $8,59 \%$ berasal dari $\frac{\text { jumlah kumlatif kelompok } A X 100}{\text { Total nilai kumulatif }}=\frac{195,5 \times 100}{2.275,144}$ kemudian memiliki prosentase penyerapan nilai rupiah sebesar $56,78 \%$ yang berasal dari $\frac{\text { jumlah nilai rupiah kelompok } A X 100}{\text { Total nilai rupiah }}$ dan menyerap dana sebesar Rp. 50.440.000 dari jumlah total nilai rupiah sebesar Rp.76.679.000.

kelompok B memiliki prosentase kumulatif sebesar $18.47 \%$ berasal dari $\frac{\text { jumlah kumlatif kelompok } B \times 100}{\text { Total nilai kumulatif }}=\frac{420,4 \times 100}{2.275,144}$ kemudian memiliki prosentase penyerapan nilai rupiah sebesar $24,15 \%$ yang berasal dari $\frac{\text { jumlahnilai rupiah kelompok } B \times 100}{\text { Total nilai rupiah }}$ dan menyerap dana sebesar Rp. 18.518.000 dari jumlah total nilai rupiah sebesar Rp.76.679.000.

kelompok C memiliki prosentase kumulatif sebesar $72,92 \%$ berasal dari $\frac{\text { jumlah kumlatif kelompok } C X 100}{\text { Total nilai kumulatif }}=\frac{1.659 \times 100}{2.275,144}$ kemudian memiliki prosentase penyerapan nilai rupiah sebesar $10 \%$ yang berasal dari $\frac{\text { jumlah nilai rupiah kelompok } C \times 100}{\text { Total nilai rupiah }}$ dan menyerap dana sebesar Rp. 7.721 .000 dari jumlah total nilai rupiah sebesar Rp.76.679.000.

\section{SIMPULAN DAN SARAN}

\section{Simpulan}

Pengendalian persediaan pada PT. Adiprima Suraprinta dapat ditarik kesimpulan sebagai berikut: 
1. Persediaan pada PT. Adiprima Suraprinta di bagi menjadi 2 jenis yaitu persediaan umun dan persediaan khusus. Persediaan umum yaitu persediaan yang digunakan diluar proses produksi misalnya masker kain, sarung tangan, persediaan ini dipesan oleh pihak gudang SPI pada PT. Adiprima Suraprinta. Persediaan khusus yaitu persediaan yang meliputi alat-alat untuk mesin produksi misalnya: batu gerinda, baut, persediaan ini dipesan masing-masing departemen yang akan membutuhkan suku cadang tersebut.

2. Persediaan suku cadang menggunakan metode analisis $A B C$ yang telah dilakukan maka dapat ditarik kesimpulan bahwa persediaan pada kelompok A terdapat 4 item, suku cadang pada kelompok B terdapat 5 item, suku cadang pada kelompok $\mathrm{C}$ terdapat 17 item. Untuk lebih jelasnya dapat dilihat pada tabel berikut:

Tabel 9. Pengelompokkan suku cadang

\begin{tabular}{|l|l|l|}
\hline Suku cadang kelompok A & Suku cadang kelompok B & Suku cadang kelompok C \\
\hline Batu Gerinda Potong 7"/180X3X22 & $\begin{array}{l}\text { Batu Gerinda Potong 4” } \\
(100 X 3 X 16)\end{array}$ & Baut L M12 X 40 SS \\
\hline Batu Gerinda Selep Dia 4/100X6X16 & Batu Gerinda Selep180X6X22 & Kawat las stainless 308 3,2 mm \\
\hline Masker kain & Baut L M12 X 25 SS & Kawat las stainless 309 2,6 mm \\
\hline Sarung tangan & Kawat Las LB-52 2,6 mm & Batu Gerinda Potong 14” \\
\hline & Kawat Las LB-52 3,2 mm & Baut L M8 X 40 SS \\
\hline & & Kawat las stainless 309 3,2 mm \\
\hline & & Baut L M6 X 30 BAJA \\
\hline & & Kawat Las RB-26 3,2 mm \\
\hline & & Kawat Las RB-26 2,6 mm \\
\hline & & $\begin{array}{l}\text { Baut L M8 X 75 mm Baja }+ \\
\text { Mur }\end{array}$ \\
\hline & & Baut L M8 X 20 SS \\
\hline & & Kawat las stainless 308 2,6 mm \\
\hline & & Baut L M6 X 60 SS \\
\hline & & Baut L M5 X 40 SS \\
\hline & & Baut L M5 X 15 SS + RING \\
\hline & & Baut L 6 X 15 SS \\
\hline & & Baut L M6X10 SS \\
\hline
\end{tabular}

\section{Saran}

Pembahasan dan kesimpulan dari hasil penelitian, maka peneliti mencoba memberikan saran sebagai berikut:

Sebaiknya, PT. Adiprima Suraprinta menggunakan metode analisis ABC untuk mengklasifikasikan persediaan suku cadang, karena persediaan suku cadang pada kelompok A dilakukan pengawasan yang lebih ketat dari suku cadang kelompok B dan Kelompok C.

\section{DAFTAR PUSTAKA}

[1]. Assauri Sofyan. 2016. Manajemen Operasi Produksi Edisi 3. PT. Raja Grofindo Persada. Jakarta.

[2]. Haizer jay and Render. 2015. Operational Management. Salemba Empat. Jakarta.

[3]. Pasca Riani Lilia, Bayu Wiyono. 2016. Analisa ABC Dalam Pengendalian Persediaan Spare Part Jenis Oli Sepeda Motor Tulungagung. https://ojs.unpkediri.ac.id/index.php/manajemen/article/view/294/282

[4]. Sudana I Made. 2011. Manajemen Keuangan Perusahaan. Erlangga. Surabaya.

[5]. https://www.kajianpustaka.com/2018/02/pengertian-fungsi-dan-jenis-persediaan-inventory.htm

[6]. https://www.adiprima.com 